$R_{i}$

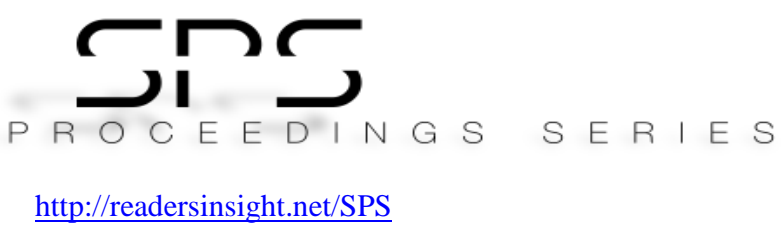

\title{
OPTICAL FIBER FAULT DETECTION AND LOCALIZATION IN AN OPTICAL ACCESS NETWORK DOMAIN
}

\author{
Auwalu Usman* \\ Lightwave Communication Research Group, Faculty of Engineering \\ Universiti Teknologi Malaysia \\ Malaysia \\ uauwalu2@graduate.utm.my \\ Nadiatulhuda Zulkifli \\ Lightwave Communication Research Group, Faculty of Engineering \\ Universiti Teknologi Malaysia \\ Malaysia \\ nadiatulhuda@utm.my \\ Mohd Rashidi Bin Salim \\ Lightwave Communication Research Group, Faculty of Engineering \\ Universiti Teknologi Malaysia \\ Malaysia \\ mrashidi@utm.my \\ Kharina Khairi \\ Fixed Infra Media Lab \\ TM Research \& Development Sdn Bhd, Selangor \\ Malaysia \\ kharina@tmrnd.com.my
}

*Corrosponding author's Email: uauwalu2@graduate.utm.my

Peer-review under responsibility of 4th Asia International Multidisciplinary Conference 2020 Scientific Committee http://connectingasia.org/scientific-committee/

(C) 2020 Published by Readers Insight Publisher, lat 306 Savoy Residencia, Block 3 F11/1,44000 Islamabad. Pakistan, editor@readersinsight.net

This is an open access article under the CC BY-NC-ND license (http://creativecommons.org/licenses/by-nc-nd/4.0/). 


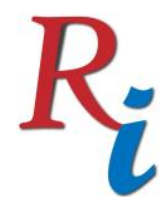

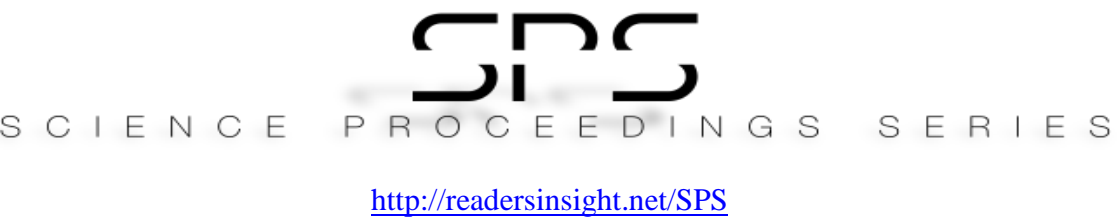

\section{A b s tract}

Fault detection and localization in optical fiber communication links are important in the optical access network (OAN) due to the passive nature of the network elements involved. Any failure in the link can resort to a huge amount of data loss in the network. However, deployment of fault detection and localization devices is extremely limited due to the reliability and financial implications of the devices. Several fault monitoring solutions in the OAN domain have been investigated by the researchers over the decades; the challenges for these monitoring techniques are the cost and complexity of their deployment. Thus, this work proposes a costeffective solution for the detection and localization of a fault in the OAN based on Fiber-tothe-x (FTTx) network using optical reflectors. The reflected signal from the monitors in the network will be utilized to detect and locate the optical link with fault. Experimental results obtained show the techniques capability to detect and localized fault in the network, in-service over a distance of $20 \mathrm{~km}$.

Keywords: Optical Fiber Fault Detection and Localization, FTTx, Optical Reflectors

\section{Rese a r ch H igh I ight s}

The monitoring technique is based on Amplified Spontaneous Emission (ASE) laser source.

The optical fiber fault can be detected by the received optical signal reflection from the optical reflectors assigned to each drop fiber in the optical distribution network (ODN).

The location of the faulty fiber link can be obtained from the experimental measurement data generated using optical power meters (OPM).

\section{Research Objectives}

The OAN is considered to be the most cost-effective access network that provides internet connectivity at a higher data rate with low power consumption $(1,2)$. However, the large scale adoption of this network imposes new challenges especially in the last mile of the network (3, 4) which is considered more vulnerable to risk, as it contains more point of optical fiber interconnection, hence, requires an effective monitoring system that is capable of detecting and localizing fault from the $\mathrm{CO}$ without deploying a technician in the field. The main objective of this research is to develop a cost-effective solution for the detection and localization of optical link fault, in OAN based on the FTTx architecture using a simple experimental approach. In the technique, an optical fiber fault detection and localization system using a 1x4 FTTx will be demonstrated. The technique uses a reflective elements at the optical distribution unit, to serve as surveillance devices that reflect the probe signal to the central office $(\mathrm{CO})$. The output of 

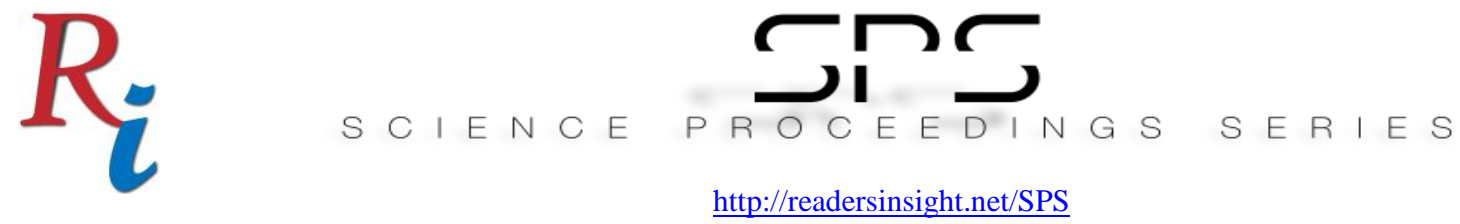

the reflector is properly analyzed to obtain the fiber fault position in the various distribution link of the network.

\section{Methodology}

Figure 1 shows the experimental setup for the proposed monitoring system, an ASE optical source generates the probe pulse, the generated pulse, and data signal are multiplexed and transmitted into the network through a 3-port CIR. The reflectors placed at the remote node $(\mathrm{RN})$ in the customer's end reflects the probe pulses. Each Drop fiber (DF) link in the network has the monitoring element placed at the point considered more vulnerable to risk. The reflected probe signal is received at port 3 of the CIR by an optical spectrum analyzer (OSA).

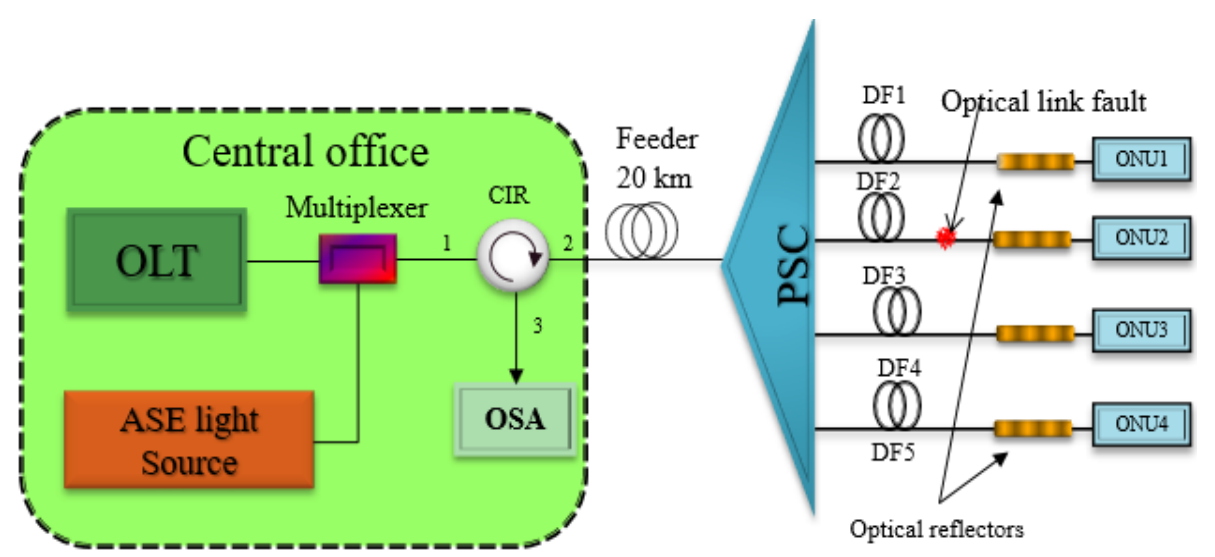

Figure 1. Proposed Optical Reflective based PON monitoring System in the FTTx network.

In order to locate the fiber fault position, after detecting the faulty optical link a measurement was conducted using OPM at the CIR port 3 and the fiber end, to obtain the corresponding values of total backscattered/reflected power with and without fault event in the optical link. These values and other fiber parameters are used to obtain the approximated fault position in the optical link using equation (1) below (5).

$$
P_{B}=P_{O} \times\left[10^{\left(-\frac{D I R}{10}\right)}+P R_{b(L)}+T_{(L)}^{2} \times 10^{\left(-\frac{R L_{a}}{10}\right)}\right] \times 10^{\left(-\frac{I L}{10}\right)}
$$

The values of $P_{B}$ and $L$ are the measured back-reflected power and fiber length with or without fault respectively, DIR, $I_{L}$, and $R_{L}$ are the directivity and insertion loss of the CIR and return loss respectively.

\section{Results}

In the measurement, the passive components of single-mode fiber (SMF), CIR, and PSC would result in the corresponding insertion loss $\left(\mathrm{I}_{\mathrm{L}}\right)$ of $0.2 \mathrm{~dB} / \mathrm{km}, 1 \mathrm{~dB}$, and $7 \mathrm{~dB}$ respectively. The 


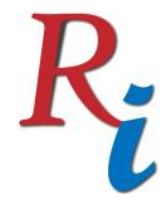

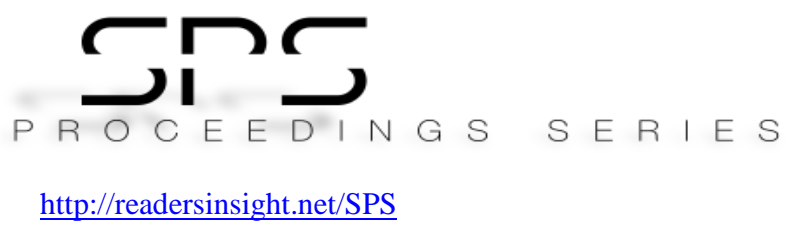

reflected signals spectra obtained at the port 3 of the CIR is shown in figure 2, it can be observed clearly from the figure that the spectrum of the DF 2 is significantly deteriorated, which indicates a link fault at that particular optical link.

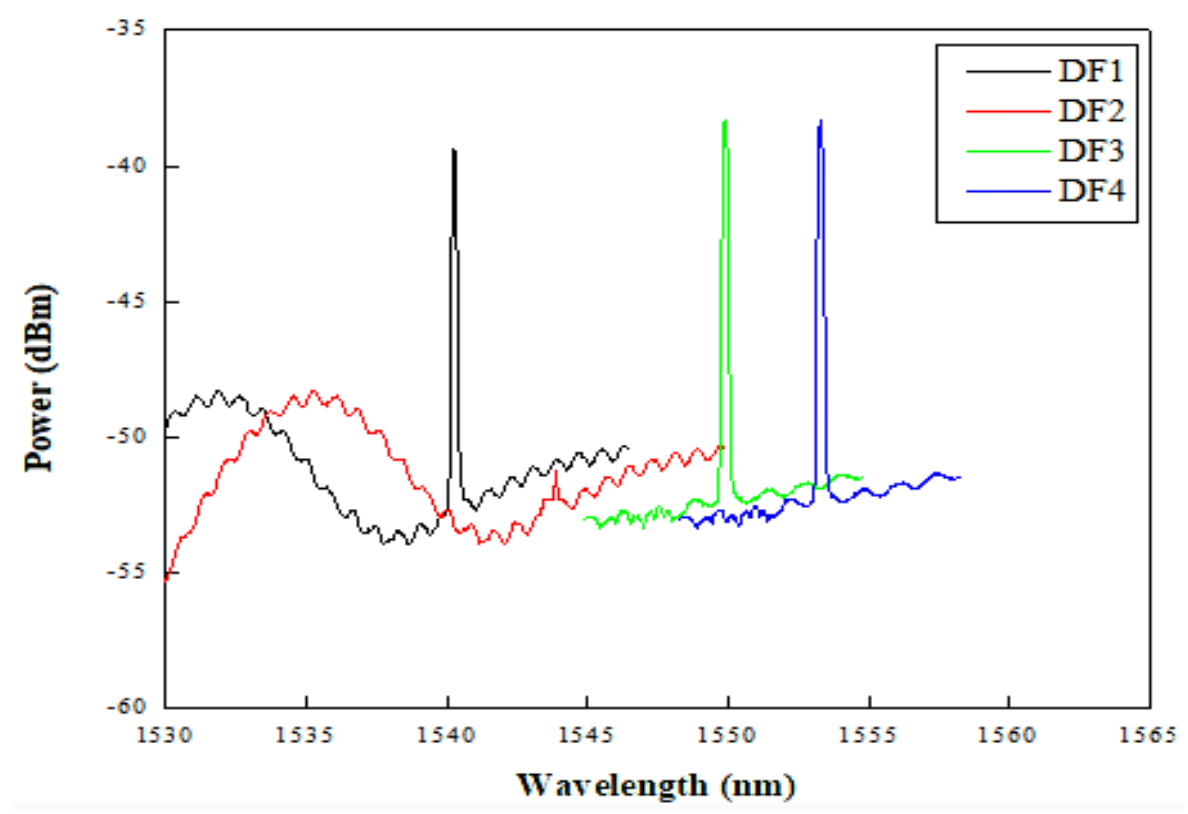

Figure 2. Signal spectra of the reflected probe signal.

The parameters used to obtain the location of the fault in the network are as follows;

The values of $P_{o}, P_{B i}$, and $P_{B o}$ are $2.68 \mathrm{mw}, 1.737 \mathrm{mw}$, and $0.933 \mathrm{mw}$ respectively, obtained through measurements using an OPM. The fiber total length is $20 \mathrm{~km}$, and the ASE wavelength is $1550 \mathrm{~nm}$. The expression in equation (1) is utilized to obtain the fault position which is approximately $10742.7 \mathrm{~m}$.

\section{Findings}

An experimental approach for optical fiber fault detection and localization in the optical network domain using optical reflectors is proposed. We utilize optical reflectors for failure detection and location in the ODN, the monitors are situated at the point closer to the user's end. The reflected signals spectra from the monitors are observed using OSA to detect and locate the fiber fault in the network. Result obtained shows the ability of the technique to detect and locate a fault at a distance of $20 \mathrm{~km}$.

\section{Acknowledgement}

The authors acknowledge the Ministry of Higher Education (MOHE) Malaysia and Research Management Centre, UTM for the financial support through the Transdisciplinary Research Grant (TDR) GUP T1, vote number 05G60 and Fundamental Research Grant Scheme, FRGS 


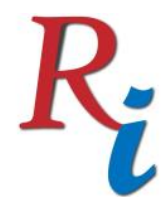

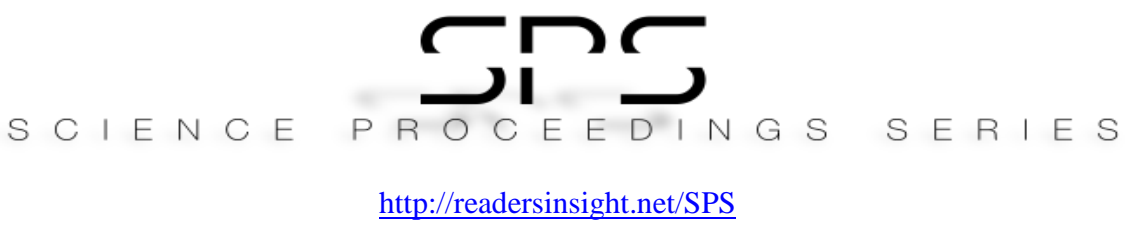

vote number 5F086. We are also grateful for the TETFUND scholarship from the Federal Government of Nigeria to the first author

\section{REFERENCES}

[1]. Ramli A, Zulkifli N, Usman A, Idrus SM. A development of optical network unit power consumption model considering traffic load effect. Jurnal Teknologi. 2018;80(4):17-22.

[2]. Bindhaiq S, Supa'at ASM, Zulkifli N, Mohammad AB, Shaddad RQ, Elmagzoub MA, et al. Recent development on time and wavelength-division multiplexed passive optical network (TWDM-PON) for next-generation passive optical network stage 2 (NG-PON2). Optical Switching and Networking. 2015;15:53-66.

[3]. Usman A, Zulkifli N, Salim MR, Khairi K. A Centralized Gigabit Passive Optical Network Fault Monitoring Using Fiber Bragg Grating Sensor. Journal of Computational and Theoretical Nanoscience. 2020;17(2):1156-62.

[4]. Usman A, Zulkifli N, Salim MR, Khairi K. An enhanced GPON Fault Monitoring Technique Using Optical Sensor. SPS. 2019;1(2):39-42.

[5]. Spirin VV, Mendieta FJ, Miridonov SV, Shlyagin MG, Chtcherbakov AA, Swart PL. Localization of a loss-inducing perturbation with variable accuracy along a test fiber using transmission-reflection analysis. IEEE Photonics Technology Letters. 2004;16(2):569-71.

\section{Author's Biography}

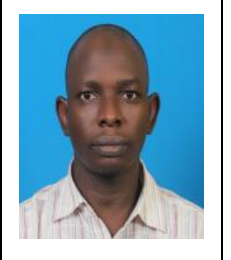

Auwalu Usman is a Ph.D. candidate in the School of Electrical Engineering University Teknologi Malaysia. He received a master's degree in Electronics and Telecommunication Engineering in 2016 from Universiti Teknologi Malaysia. His research interest is in optical engineering specialized in Passive optical networks. He is an academic staff at Kano State Polytechnic Kano Nigeria. 